Wisconsin, contiguous with his area of distribution. The third exception represents a thus far isolated occurrence in Pennsylvania.

On November 10, Dr. Patterson informed me that since his last publication, he has received a large number of additional records, including some from Minnesota, North Dakota, Wisconsin, and Canada. This leaves as a new contribution on my part only the occurrences in Louisiana and Pennsylvania.

HaNs E. Fischel

Department of Anthropology

Berkeley, California

\title{
FOLSOM AND YUMA POINTS FROM SASKATCHEWAN
}

Several years ago, after intensive studies of the Folsom "problem," it seemed to be apparent that the more finely chipped Folsom and Yuma points were coming from the Great Plains province. This, in general, has been shown by evidence produced principally from New Mexico, Colorado, and Nebraska.

It was logical therefore to expect similar evidence to be forthcoming from the Great Plains region of Canada. Two men in Saskatchewan: Kenneth H. Jones of Mortlach and Burt S. Gunn of Pense, have been finding beautifully flaked points of the above types for the past several years in the southern part of the province, near Regina, under conditions that are almost identical to those prevailing where similar points are found within the United States. D. J. McKillop of Regina also had a number of Yuma points in a collection that he showed to me.

Having been in correspondence with Mr. Jones for several years, I had promised myself at the end of each summer's field work to make a trip to Saskatchewan and see these localities for myself. It was not till the end of August and the early part of September of last year that I was able to carry out this intention. I spent several days in and around Mortlach and the country between there and Regina, which offered an opportunity for investigation of the areas from which both Folsom and Yuma points had been reported, and to study the collections made by Mr. Jones, Mr. Gunn, and others.

The same pattern is discernible here as in other Folsom and Yuma sites. The points are not only similar, but they are coming from areas that show the same unmistakable signs of a changing environment. All are from places that have been eroded by the wind. These places are described by those who have found them as "blow-outs," "wind-blown bottoms of small dry lakes," and "shallow wind-blown ravines."

The sites from which the collections of Folsom and Yuma points were made roughly comprise a fan-shaped area northwest, west, and southwest of Regina, with a radius stretching west about one hundred miles and northwest to the South Saskatchewan River. Some, however, were said to have come from southeast of Regina, in the sand hills near Estevan. The area which I investigated was mostly that in proximity to Mortlach, about seventy-three miles 
west of Ragina. The principal sites from which Mr. Jones had secured his specimens were from three-quarters of a mile to two miles north and slightly east of the town of Mortlach. Mr. Gunn's Yuma points are from the districts of Osage, Pontiex, and Pense.

In this sector, west and northwest of Regina, as the sectional maps of the Canadian Government show, are many non-perennial streams and non-permanent lakes, which during periods of prolonged drought such as have occurred in recent years, are greatly eroded by the wind. The flood plains of the small streams, the dry basins and "blow-outs," caused by the breaking up of the land by the plow, are the places which were pointed out to me as those where Folsom and Yuma points have been picked up.

Quoting from a letter from $\mathrm{Mr}$. Gunn relative to some of the points which appear in the accompanying plates, he refers to his most important site as a typical "blow-out," ". . . erosion having proceeded to a depth which I estimate to be three and a half feet. Erosion islands show that about eighteen inches of the original top soil was a dark brown, sandy loam, after which the texture graduated rapidly to a fine yellow sand which goes down to an unknown depth. This sand is of glacial origin. I have been sufficiently familiar with this particular site during the past four years to say definitely that the Yuma complex was not present in the dark brown upper soil, although there was no lack of the more recent plains types of projectile points in it. It was apparently at about the eighteen-inch level that the Yuma types started to show up, together with their associated artifacts, and a few are still coming to light although weather conditions during the past summer have been such that little further erosion has taken place."

As for the artifacts themselves, the plates show the best examples. The similarity to types from Texas, New Mexico, Colorado, Nebraska, and some of the bordering states is readily observed. Three of the specimens shown are Folsom types. Mr. Jones has found an additional one since I was at Mortlach, and judging from his drawing, it is obviously Folsom. The other points shown are all Yuma types.

Plate 13 shows the flaking art at its best. All are patinated on one side and are made of a chalcedonic material. Number 1 belongs to Mr. Gunn, and numbers 2 and 3 to $\mathrm{Mr}$. Jones.

Plate 14, Figure 1, reading from left to right, beginning at the top, shows: numbers 1-3, leaf-shaped points with no fluting on the faces. Numbers 4-6, Folsom points, though the fluting is not very easy to see in the photographs. All of these belong to Mr. Jones, and can be duplicated from collections made at Clovis, New Mexico, and from Texas and other sites in the Great Plains region of the United States. Number 5 is the broken base of a Folsom and is exactly like specimens from Folsom and Clovis, New Mexico, and sites in Texas and Colorado. Number 6 is almost an exact duplicate of one from southwestern Kansas, except that the material is red jasper instead of a white quartzite.

Plate 14, Figure 2, shows Yuma types. Number 1 is of a reddish-yellow 


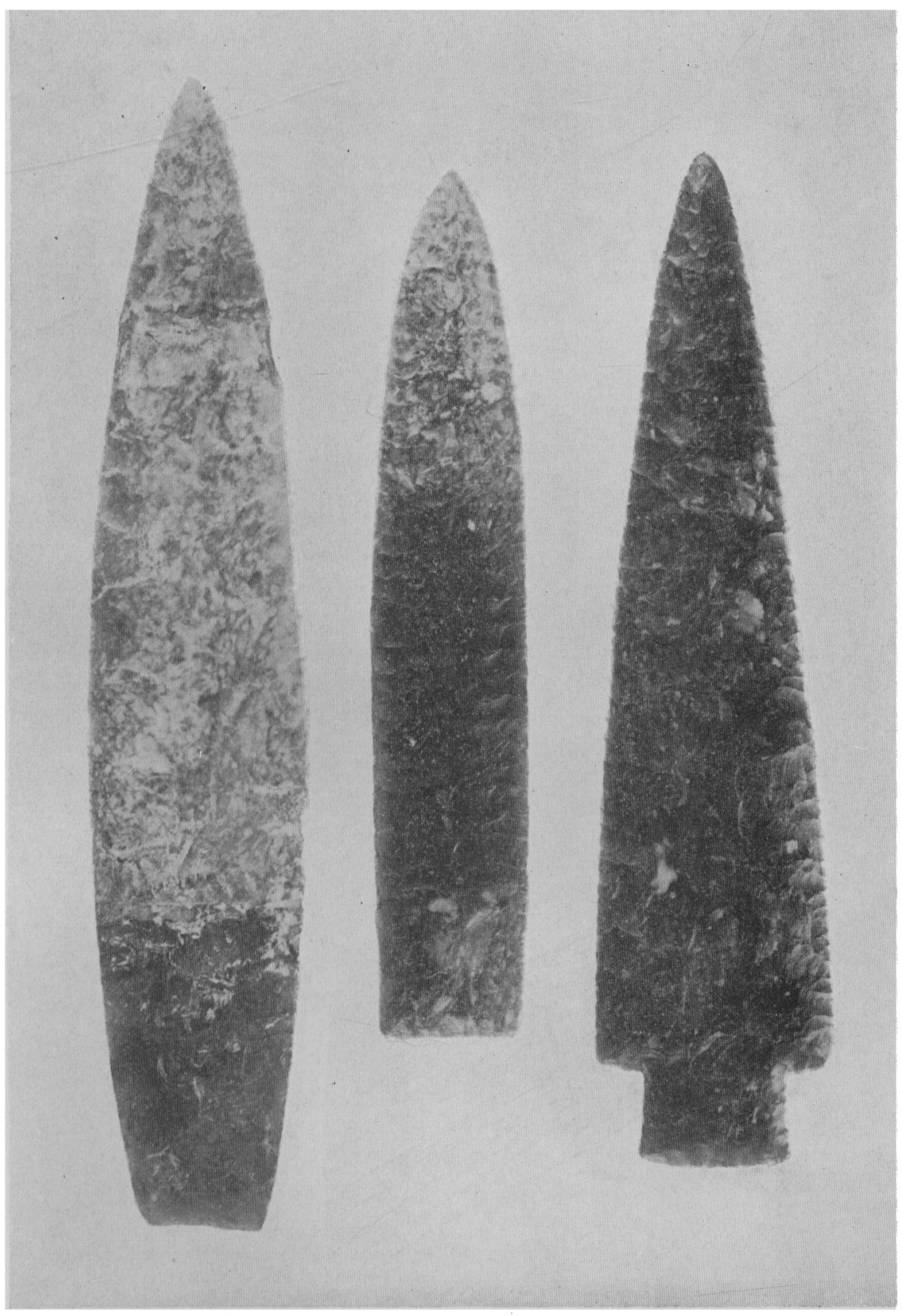

Actual size. 
[AMERICAN ANTIQUITY, VOL. 4

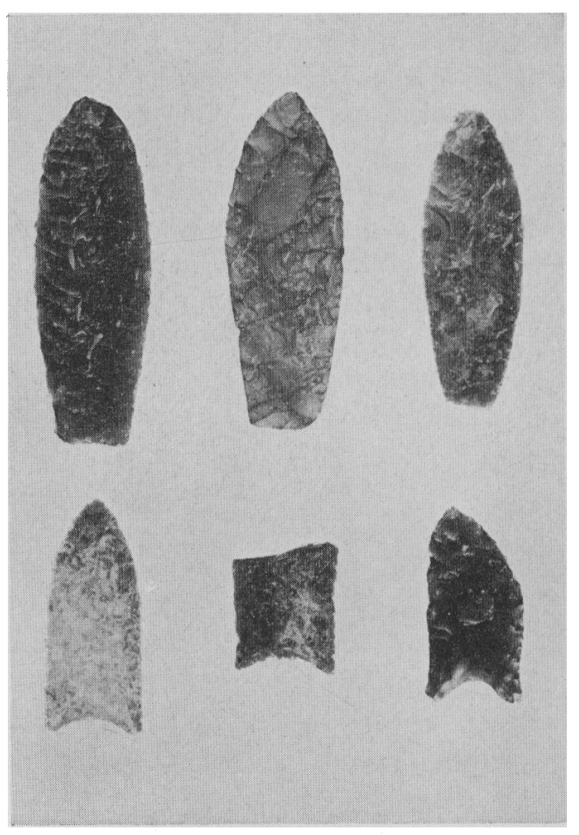

Fig. 1.-Scale $\frac{1}{2}$.

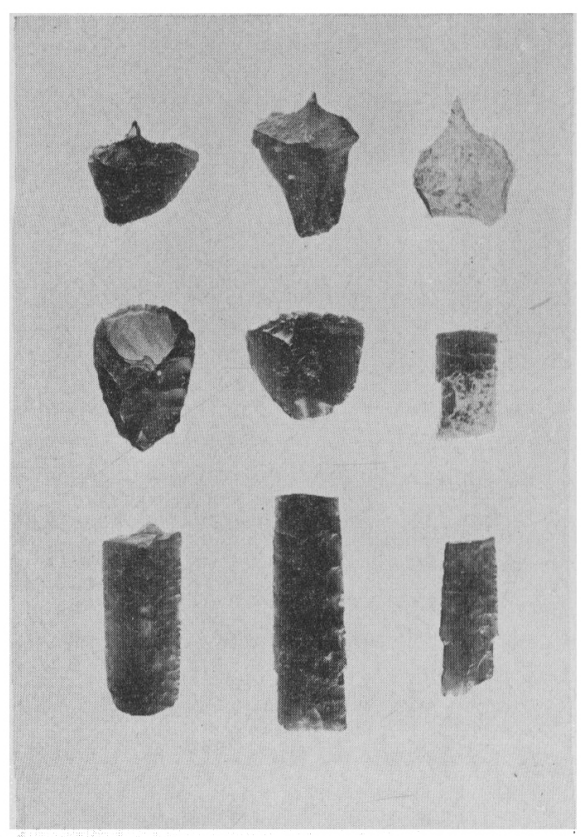

Fig, 3.--Scale $\frac{1}{2}$.
PLATE 14]

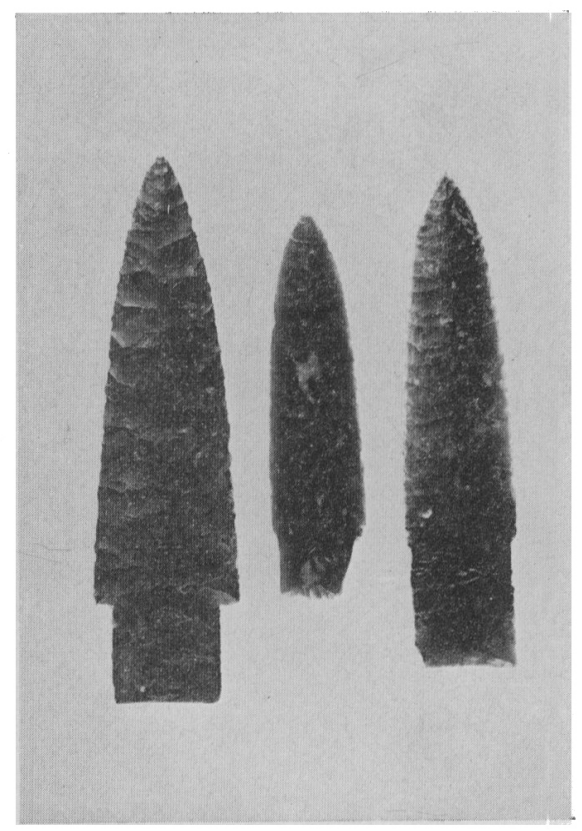

FIG. 2.-Scale $\frac{1}{2}$.

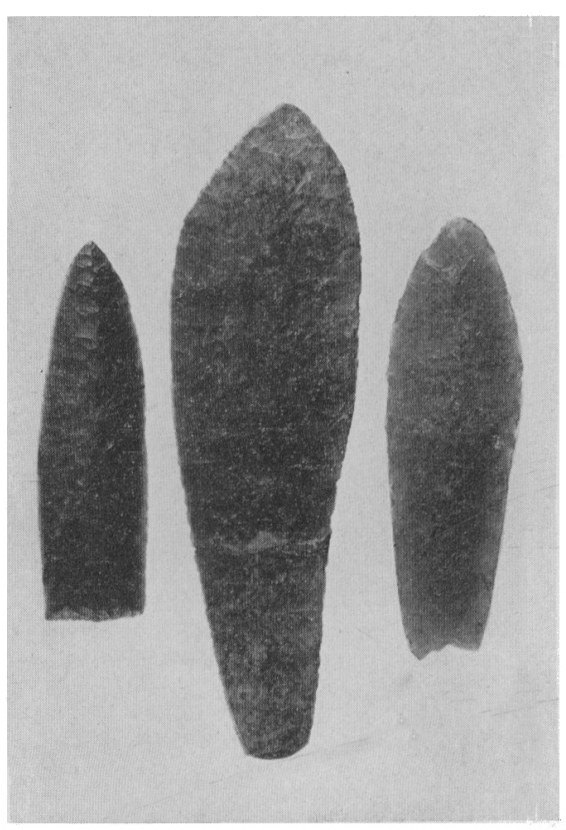

FIG. 4.-Scale $\frac{1}{2}$. 
jasper, polished like old furniture; numbers 2 and 3 , of a brownish chalcedony, patinated on one side. Number 1 would be classed by Renaud as his Type 4b. Numbers 1 and 2 belong to Mr. Gunn, and Number 3 to Mr. Jones.

Plate 14, Figure 3, shows small gravers exactly like specimens from the Lindenmeier site in Colorado, and from Clovis, New Mexico; also small scrapers of jasper, and fragments of Yuma tools, with fine secondary chipping along the edges. Numbers 1-5 belong to Mr. Gunn, and numbers 6-9 to Mr. Jones.

Plate 14, Figure 4, shows an interesting blade of chalcedony, placed between two others for comparison. It is very thin, and is heavily patinated on one side only. These were acquired for the University Museum, Philadelphia, and were said, by Mr. McKillop, of Regina, to have come from the same sort of "blowout" as the others in this region. While it has a sort of Solutrean leaf-blade look about it, the flaking seems to be finer than on the French blades.

All credit is due Messrs. Jones and Gunn for their interest in their local archaeology, for their keen observation, and for reporting their discoveries for the purpose of aiding in a broader knowledge of the subject. Thus they have extended northward, through the Great Plains, evidence that Folsom man had passed that way at some time or other in his pursuit of the herds of bison and other animals that lived contemporaneously with him.

Many bison bones were seen in the various "blow-outs" visited, some obviously recent; others, however, giving the appearance of being in place in the bluish silts which at one time covered them to a greater depth than now observed. Several specimens of vertebrae, shoulder blades, and so on, were removed from considerable depths below the present surface of the "blow-outs." Whether enough of the skeleton was recovered to make a proper identification is doubtful as no skulls were seen. No mammoth remains were found. A more intensive search might reveal a closer association of human artifacts with extinct bison and possibly mammoth bones in these Saskatchewan "blowouts." It has already been pointed out how strikingly similar is the appearance of these "blow-outs" or basins to those at Clovis, New Mexico. These brief notes are recorded with the hope that further and more extended research can be undertaken by others working upon this problem.

Edgar B. Howard

University Museum

Philadelphia, Pa. 